NBER WORKING PAPER SERIES

\title{
DO BORROWING CONSTRAINTS MATTER? AN ANALYSIS OF WHY THE PERMANENT INCOME HYPOTHESIS DOES NOT APPLY IN JAPAN
}

\author{
Miki Kohara \\ Charles Yuji Horioka \\ Working Paper 12330 \\ http://www.nber.org/papers/w12330
NATIONAL BUREAU OF ECONOMIC RESEARCH
1050 Massachusetts Avenue
Cambridge, MA 02138
June 2006

The authors are grateful to Kenn Ariga, Anton Braun, Robert Dekle, Yasushi Hamao, Fumio Hayashi, Yasushi Iwamoto, Shizuka Sekita, Toshiaki Tachibanaki, and seminar participants at Osaka University and the University of Tokyo for their valuable comments and to the Ministry of Education, Culture, Sports, Science and Technology of the Japanese Government for Grant-in-Aid for Scientific Research number 12124207, which supported this research. Forthcoming in Japan and the World Economy, vol. 18, no. 4 (2006). The views expressed herein are those of the author(s) and do not necessarily reflect the views of the National Bureau of Economic Research.

(C2006 by Miki Kohara and Charles Yuji Horioka. All rights reserved. Short sections of text, not to exceed two paragraphs, may be quoted without explicit permission provided that full credit, including $\odot$ notice, is given to the source. 
Do Borrowing Constraints Matter? An Analysis of Why the Permanent Income Hypothesis Does Not Apply in Japan

Miki Kohara and Charles Yuji Horioka

NBER Working Paper No. 12330

June 2006

JEL No. D1, D9, E2, G1

\begin{abstract}
We use micro data on young married households from the Japanese Panel Survey of Consumers in order to analyze the importance of borrowing constraints in Japan. We find (1) that 8 to 15 percent of young married Japanese households are borrowing-constrained, (2) that household assets and the husband's educational attainment are the most important determinants of whether or not a household is borrowing-constrained, and (3) that the Euler equation implication is rejected for both the full sample and for the subsample of unconstrained households. These results suggest that the life cycle/permanent income hypothesis does not apply in Japan and that the presence of borrowing constraints is not the main reason why it does not apply.

Miki Kohara

Osaka School of International Public Policy

1-31, Machikaneyama

Toyonaka, Osaka 560-0043

JAPAN

kohara@osipp.osaka-u.ac.jp

Charles Yuji Horioka

Institute of Social and Economic Research

Osaka University

6-1, Mihogaoka

Ibaraki, Osaka 567-0047

JAPAN

and NBER

horioka@iser.osaka-u.ac.jp
\end{abstract}




\section{Introduction}

If the life cycle/permanent income hypothesis (hereafter LCPIH) holds, changes in consumption should not be sensitive to changes in expected income. On the other hand, if this hypothesis does not hold (for example, because households are borrowing-constrained), changes in consumption will be sensitive to changes in expected income. Thus, a commonly used test of the validity of the LCPIH is to estimate an Euler equation to see whether changes in consumption are sensitive to changes in expected income.

If the LCPIH does not hold and the reason is the existence of borrowing constraints, we would expect changes in consumption to be sensitive to changes in expected income in the case of borrowing-constrained households but not in the case of unconstrained households. In this paper, we use micro data on young married households from the Japanese Panel Survey of Consumers, conducted by the Institute for Research on Household Economics, to shed light on (1) the prevalence of borrowing constraints in Japan, (2) what households are borrowing-constrained in Japan, (3) whether the LCPIH holds in Japan, and (4) whether the presence of borrowing constraints is the reason why the LCPIH does not hold in Japan.

To summarize our main findings, we find (1) that 8-15 percent of young married Japanese households are borrowing-constrained, (2) that household assets and the husband's educational attainment are the most important determinants of whether or not a household is borrowing-constrained, and (3) that the Euler equation implication is rejected for both the full sample and for the subsample of unconstrained 
households. These results suggest that the LCPIH does not apply in Japan and that the presence of borrowing constraints is not the main reason why it does not apply.

The paper is organized as follows: in Section 2, we present the theoretical model; in Section 3, we describe the data and analyze what households are borrowingconstrained in Japan; in Section 4, we present the results of our Euler equation tests; and Section 5 concludes.

\section{The Model}

\subsection{Consumption Smoothing}

Consumption smoothing behavior is characterized by the Euler equation. We summarize this, making the usual assumptions. An individual holds $A_{t}$ of total assets at the beginning of period $t$ and purchases a total of $N_{t}$ of assets at (the end of) $t$. The individual earns a real wage of $w$, and spends it on the consumption of goods, $c$, and the purchase of assets, $N$. We do not consider the individual's leisure choice, and assume $w$ is exogenous. The saving constraint faced by the consumer is described as $N_{t}-A_{t}=w_{t}-c_{t}$. The asset accumulation constraint is $A_{t+1}=N_{t}\left(1+r_{t+1}\right)$ where $r_{t+1}$ is the interest rate at the beginning of period $t+1$. All individuals face the same interest rate, live for a finite lifetime $T$, and leave no bequests at $T+1$. Suppose that the individual's utility is stationary and additively separable over time and written as $E_{t}\left\{\sum_{k=t}^{T} \frac{1}{(1+\rho)^{k-t}} u\left(c_{k}\right)\right\}$, where $E_{t}$ is an expectation operator conditional on information available at $t, u$ is a function that is increasing and concave in $c_{t}$ and $\rho$ is the rate of time preference, which is assumed to be homogeneous over individuals 
and time. The representative consumer's maximization problem can be written as a dynamic programming problem. Maximizing $V_{t}=u\left(c_{t}\right)+\frac{1}{1+\rho} E_{t} V_{t+1}\left(A_{t+1}, w_{t+1}\right)$, we obtain the first order condition for consumption: $E_{t}\left\{\frac{\partial u_{t}}{\partial c_{t}}-\frac{1+r_{t+1}}{1+\rho} \frac{\partial u_{t+1}}{\partial c_{t+1}}\right\}=0$. This is the Euler equation, implying consumption at $t$ should be chosen so that the expected discounted gain of saving now for the future is equal to marginal utility in this period. Further assume that utility is isoelastic, $u\left(c_{i t}\right)=c_{i t}^{1-\gamma} / 1-\gamma$, where $\gamma$ is the risk aversion parameter. Marginal utility is convex and allows for precautionary saving as a special case. If it is assumed that $\ln c_{i, t+1}$ and $r_{t+1}$ have a joint normal distribution, the Euler equation becomes

$$
E_{t} \Delta \ln c_{i, t+1}=\gamma^{-1}\left(E_{t} r_{t+1}-\rho\right)+\frac{1}{2} \gamma \omega_{i, t}^{2}
$$

In the last term, $\omega_{i, t}^{2}$ is the conditional variance, which equals the variance of $\left(\Delta \ln c_{i, t+1}-r_{t+1} / \gamma\right)$ and partly reflects uncertainty and the precautionary motive for saving.

There are at least two ways to test the validity of equation (1). The first way is to test a structural form, estimating utility function parameters using Generalized Method of Moments (nonlinear instrumental variable) estimation. This is a direct test using the Euler equation, whose error term should be orthogonal to information before $t$ (see, for example, Runkle (1991)). GMM estimation is beneficial in the sense that we can avoid the approximation of linear marginal utility in consumption, the assumption of distribution, and the assumption of income exogeneity.

However, many researchers have for a long time used another way to test the 
Euler equation implication. This is a test of the reduced form Euler equation with additional variables in past information sets. It tests the validity of this additional information (for example, income changes) predicted by previous information. Additional variables should not explain consumption changes if the Euler equation holds. For example, consumption changes should not react to predicted income changes. That is, we test whether $\beta=0$ in the equation

$$
\Delta \ln c_{i, t+1}=\alpha_{1} F_{t}+\alpha_{2} \Delta X_{i, t+1}+\alpha_{3} \frac{1}{2} \gamma \omega_{i, t}^{2}+\beta \Delta \ln y_{i, t+1}^{e}+\varepsilon_{i, t+1}
$$

where $\Delta \ln y_{i, t+1}^{e}$ is income predicted by individuals using the information available to them. This is calculated as predicted values from the first stage estimation of $\Delta \ln y_{i, t+1} . F_{t}$ is a time-varying variable including $\gamma^{-1}\left(E_{t} r_{t+1}-\rho\right)$. Preference shifts, described as $\Delta X_{i, t}$, could affect the consumption plan at any point in time. The third term is the conditional variance of the uncertain components. One of our main focuses is to review past studies using proper data on consumption smoothing. Thus, we conduct this reduced form exclusion test. Since our data are panel data on households, we conduct IV estimation controlling for household-specific differences by applying fixed effects estimation and random effects estimation. The null hypothesis is that the Euler equation holds and that individuals smooth consumption changes against predicted income changes. That is, $\beta=0$ : consumption does not react to predicted income changes.

Most past studies drop the conditional variance term, $\frac{1}{2} \gamma \omega_{i, t}^{2}$, simply assuming that it is the same across individuals. It is often necessary to make this assumption 
because information is seldom available on precautionary motives, but Jappelli and Pistafferri (2000) emphasize the importance of including this term; if we ignore this term and if $\Delta \ln y_{i, t+1}^{e}$ is related to uncertainty or precautionary saving motives, $\beta$ measures not the sensitivity of consumption to income but the effect of uncertainty on consumption. Jappelli and Pistaferri (2000) regard nominal (observable) income variance as a proxy for the uncertainty term $\gamma \omega_{i, t}^{2}$ and include it as one of the explanatory variables.

This method could, however, be problematic for the following reasons: First, income uncertainty is only one of many uncertainties individuals face and is not a sufficient indicator of general uncertainty. Second, even if uncertainty consists only of income uncertainty, using actual income uncertainty as a proxy for $\gamma \omega_{i, t}^{2}$ as well as $\Delta \ln y_{i, t+1}^{e}$ may raise a problem due to the correlation between the two. Thus, we calculate consumption variances for each household, and conduct an additional test of the Euler equation implication controlling for this term.

\section{$2.2 \quad$ Violation of Consumption Smoothing}

If markets are complete and there exist appropriate securities against any future state, each household's consumption is fully insured against any idiosyncratic shock. Households can smooth consumption changes completely over expected and unexpected income fluctuations, sharing risks with each other. Previous studies have tested this implication of consumption full insurance and most have rejected it. Although it is important to find a situation (if any) where full insurance holds, the rejection of the implication is not surprising. A more interesting issue is what can 
and what cannot explain the violation of the implication.

For example, the existence of borrowing constraints may cause the Euler equation implication to be rejected. Many studies have, for a long time, inquired into the existence of borrowing constraints and the differences in consumption behavior between borrowing-constrained and unconstrained households. Households should fail to smooth consumption if they encountered an unexpected shock and could not borrow to carry out their original plans. Thus, unconstrained households should not react to income shocks, while constrained households should react strongly. Based on this analogy, many researchers have tested the Euler equation (e.g., Eq. (2)) and have interpreted $\beta$ as the proportion of borrowing-constrained households.

Once we have rejected the Euler equation implication, we should seek the reason for it, checking each possible explanation one by one. The following parts focus on the existence of borrowing constraints, which is the most frequently used explanation for the violation of the Euler equation implication. Specifically, we identify unconstrained households using unique information on households' borrowing constraints and test the Euler equation implication using this subsample. If the existence of borrowing constraints is the primary explanation for the violation of the Euler equation implication, we should find evidence of the Euler equation implication for this sample but not for the full sample. However, if other explanations for the violation of the Euler equation implication matter, we should not find support for this implication even for the unconstrained sample. We will discuss other possible explanations for the violation of the Euler equation implication later after we have examined the empirical results for borrowing constraints. 


\section{The Data}

\subsection{JPSC Data}

This paper uses micro data from the Japanese Panel Survey of Consumers, (hereafter the JPSC) (in Japanese, Shouhi Seikatsu ni kansuru Paneru Chousa), a panel survey conducted by the Institute for Research on Household Economics (in Japanese, Kakei Keizai Kenkyuusho). This survey has surveyed young married and unmarried women (those between the ages of 24 and 34 in 1993) once a year since 1993, and this paper uses the 1993-2004 waves from this survey. Because JPSC is a panel survey, we can calculate changes in consumption from year to year, which is precisely the variable we need to test our theoretical model. We confine our analysis to the subsample of married women because most young single Japanese women live with their parents and rely on their parents' income but precise information is not available on their parents' income and consumption. Note that married women are asked not only about themselves but also about other household members.

Borrowing constraints. The first and most important variable used in our analysis is the one pertaining to borrowing constraints. The JPSC asks three unique questions about borrowing constraints: (1) Have you (or your spouse) ever had a loan application turned down? (2) Have you (or your spouse) ever had the loan amount reduced when you applied for a loan? (3) Have you (or your spouse) ever decided against applying for a loan because you expected your loan application to be turned down? Following Jappelli (1990), we refer to households answering "yes" to these questions as "rejected," "reduced," and "discouraged" borrowers, respectively. 
Households that replied "yes" to one or more of these questions were regarded as being borrowing-constrained. Unfortunately, this information is available only in the 1993 wave and the 1998 and later waves $^{1}$. Thus, we had no choice but to assume that borrowing constraints remained unchanged during years for which information is not available. This is exactly what Jappelli (1990) and Jappelli, Pischke, and Souleles (1998) assume, even though it may be too strong an assumption. We will return to this point in the last part of this section.

Consumption. The JPSC collects data on consumption (living expenses) by all household members during the month of September. In the regression analysis, we use the growth rate of monthly consumption. The data on monthly consumption have at least two advantages: first, they include all consumption goods and services, unlike in the case of PSID, which collects data only on food consumption. Thus, we need not make any assumptions about the separability of consumption. Second, using the change in consumption between two non-sequential months has the advantage of avoiding, to some extent, potentially serious problems raised by consumption durability and habit formation ${ }^{2}$.

Income. The JPSC collects data on several measures of income, including annual

\footnotetext{
${ }^{1}$ More specifically, the wording of the question about borrowing constraints was changed slightly starting in 2003, and it now asks only about the respondent's experience during the previous year. For 2003 and later, we have created a new variable that indicates whether the respondent was borrowing constrained at any point in the past.

${ }^{2}$ The change in monthly consumption could be biased if the household engages in purchases of big-ticket items such as homes and cars. The JPSC asks about spending on 'living expenses' during the previous month excluding spending on most big-ticket items. The survey asks separately about purchases financed by loans. Thus, we can exclude the possibility that consumption growth is overestimated as a result of purchases of big-ticket items. Unfortunately, the JPSC does not ask for a breakdown of living expenses into durables, non-durables, and services so we cannot be sure that it excludes durables completely, but for the reason given above, we can be reasonably sure that it consists mostly of non-durables and services, which is what we want.
} 
(total) income, annual labor income, and monthly labor income. Annual (total) income and annual labor income are inclusive of taxes so we need to estimate taxes in order to calculate after-tax income. We use after-tax monthly labor income in the main Euler equation for at least three reasons: first, we wanted the period and timing of consumption and income to match. If we use annual income, there is a danger of underestimating the degree of consumption smoothing simply because annual income is more stable than monthly income or consumption. Another reason for using monthly income is that using annual income would require us to waste the last year of data since the survey asks about annual income in the previous year. Finally, the use of monthly labor income helps to reduce the amount of household heterogeneity because data on monthly labor income are not available for the selfemployed. We sum the monthly labor incomes of all household members and use the growth rate of total monthly labor income in the regressions.

Household characteristics. Following the past literature on testing the LCPIH and the existence of borrowing constraints by estimating an Euler equation, we include the husband's age, the household's consumption needs, as proxied by the number of family members, and year dummies. Although we tried including many other time-variant and time-invariant variables that might possibly influence consumption, particularly that of young Japanese households such as those included in our sample, all of the variables we tried including had little effect and their inclusion was not supported statistically ${ }^{3}$. Time-invariant variables such as regional dummies

\footnotetext{
${ }^{3}$ For example, neither a dummy variable for those who had their first baby during the current year, which could make a big difference in consumption patterns, nor a dummy variable for those who starting living with their parents during the current year, which is often observed in Japan as
} 
are automatically dropped in the case of fixed effects estimation. We estimate expected income change using income change in the previous year and the husband's educational attainment as instruments and include it in the explanatory variables for consumption.

The total number of married women (households) was about 1000 in most years. In order to estimate the Euler equation, we kept an observation if it contained enough information for at least a one-year panel. Thus, the sample we used is an unbalanced panel. We calculated consumption variances using consumption values for the past four years, and information on borrowing constraints is available for 1993 and for 1998 and later. Thus, data for 1998 to 2004 are used to test the Euler equation implication. After eliminating observations with missing values for one or more of the variables included in the regressions, we were left with 1006 households (4582 household-years) in the full sample and 956 households (4133 household-years) in the unconstrained sample ${ }^{4}$.

\subsection{Who Is Constrained?}

Before estimating the Euler equation, we summarize the characteristics of borrowingconstrained households. Table 1 summarizes the borrowing motives of households that are currently in debt. Although housing and car purchases are the main reasons for borrowing, a few households do in fact borrow to finance living expenses. More

the parents get older, changed the results below.

${ }^{4}$ We did not drop outliers from our sample in the regression results shown in this paper. We did try re-estimating the regressions after dropping observations whose monthly consumption and disposable income lie outside of the "mean plus or minus three standard deviations" range, but the results did not change qualitatively. 
than half of the sample is currently in debt, which suggests that borrowing plays an important role in household planning.

Turning to data on the share of households that are borrowing-constrained, this figure was 7.61 percent in 1993, 9.29 percent in 1998, and 15.40 percent in 2003. Thus, the share of borrowing constrained households was very low in 1993, and although it increased sharply during the 1990's and early 2000's, it was still less than one-sixth in 2003.

Many past studies have tried to distinguish borrowing-constrained households from unconstrained households. Since direct data on borrowing constraints are usually not available, most previous studies have tried to predict who is borrowingconstrained using a variety of indicators. In our case as well as in the case of Jappelli (1990), however, direct information is available on whether or not a given household is borrowing-constrained. Thus, following Jappelli (1990), we analyze what determines whether a given household is borrowing-constrained by regressing a dummy variable that equals one if the household is borrowing-constrained and zero otherwise on various household characteristics using probit estimation. The household characteristics we use include assets, income, the husband's age and educational attainment, household size, homeownership, debt, city size, and region. We use two measures of assets: Asset1, which is defined as holdings of bank and postal deposits, bonds, and equities, and Asset2, which is defined as Asset1 plus life and non-life insurance, land, and housing. Only the results for Asset1 are shown in Table 3, but the results for Asset2 were qualitatively similar. Debt is defined as the amount of outstanding debt. The other variables are described in the previous section. 
Table 2 shows the characteristics of borrowing-constrained and unconstrained households separately. All borrowing-constrained households have lower assets and husband's educational attainment than unconstrained households and all borrowingconstrained households with the exception of "reduced" households have lower incomes and husband's employment rate than unconstrained households. "Discouraged" borrowers have similar characteristics to "denied" and "reduced" households. This finding underscores the importance of differentiating "discouraged" households from those completely free from borrowing constraints and grouping them together with borrowing-constrained households.

Who is borrowing-constrained? Table 3 shows the estimation results of our probit analysis of who is borrowing-constrained for 1993, 1998, and 2003. Household assets and income are two variables of interest since many past studies have used the ratio of assets to income as an indicator of whether or not a given household is borrowing-constrained, and as Table 3 shows, the marginal effects of the incomerelated variables are statistically significant in only one of the 3 years (1998), but the marginal effects of Asset and/or Asset-squared are statistically significant in all 3 years, with the overall impact of assets being consistently negative, as can be seen from the partial effects on the last line of Table $3^{5}$. However, we found that the husband's educational attainment also has a statistically significant impact on the probability of being borrowing-constrained in the case of Japan, with college grad-

\footnotetext{
${ }^{5}$ The partial effect of Asset on the probability of being constrained is calculated as $\varphi(\mathbf{X} \boldsymbol{\beta})$. $\left(\beta_{1}+2 \beta_{2}\right.$ Asset $^{+}+\beta_{3}$ Income $^{+}+\beta_{4}$ HusAge $\left.^{+}\right)$, where upper plus indicates the mean value and $\beta_{1}, \beta_{2}, \beta_{3}$, and $\beta_{4}$ are the coefficients of Asset, Asset-squared, the cross-product of Asset and Income, and the cross-product of Asset and HusAge, respectively. $\varphi(\cdot)$ is the standard normal density function, and $\mathbf{X} \boldsymbol{\beta}$ is the linear prediction evaluated at the means.
} 
uates being significantly less likely to be borrowing constrained than less educated households. The results are unchanged even if we utilize the panel structure of the data and do, say, a random effects logit estimation using 1993 and 1998-2004 data. Jappelli (1990) found using U. S. data that income and assets have a significant impact on the probability of being borrowing constrained but that the husband's educational attainment does not, so our results for income and husband's educational attainment are different from those for the United States. Educational attainment could be an indicator of current as well as future income, and a household in which the educational attainment of the husband (usually the household head and main income earner) is relatively low might be regarded as having insufficient ability to repay loans.

Finally, we also tried including a number of other explanatory variables, but their coefficients were never significant ${ }^{6}$.

We turn now to a check of the accuracy of indicators used by previous studies to identify borrowing-contrained and unconstrained households. Following previous studies, we group the sample into 'hypothetically' borrowing-constrained and unconstrained households using various indicators and then compare these households to 'actually' borrowing-constrained and unconstrained households. The results are shown in Table 4.

The first three indicators, which were originally proposed by Zeldes (1989), are

\footnotetext{
${ }^{6}$ The self-employed may need to borrow and may face borrowing constraints more frequently than others. Also, employment conditions such as tenure and firm size often affect household decisions in Japan. Thus, we conducted the estimation including variables relating to the husband's self-employement, tenure, and firm size, but none of their coefficients were significant.
} 
the most frequently used indicators in many countries and are constructed by taking the ratio of asset holdings to income. Since households who have adequate amounts of assets relative to income can dissave their assets when necessary and protect their consumption against unexpected income shocks, households with a high assetincome ratio are regarded as being unconstrained. The first indicator is whether or not the household's holdings of financial assets are more than twice as much as their monthly income, and the second one is whether or not the household's holdings of total assets (financial assets plus housing equity) are more than twice their monthly income. The third indicator classifies households with no financial assets as being borrowing-constrained and households whose holdings of financial assets are more than twice their monthly income as being unconstrained.

The fourth indicator is whether or not the household owns one or more credit cards. If it owns one ore more credit cards, it can finance its consumption even when it experiences an unexpected income decline. This indicator is close to the one suggested by Shintani (1994), who classifies households as being unconstrained if they own one or more credit cards or one or more cards with a free-loan feature because they need to pass a credit check in order to receive one or both kinds of cards. The fifth indicator, proposed by Hayashi (1985b), classifies households as unconstrained if they consume less than 85 percent of their annual disposable income (minus all debt outstanding plus 20 percent of their financial assets).

Finally, since we found from Table 3 that educational attainment is a significant indicator of being unconstrained, we propose a new indicator that identifies college graduates as being unconstrained. In addition, we construct another new indicator 
that is the same as the first indicator suggested by Zeldes (1989) except that financial assets are replaced by a broader concept of assets-namely, bank and postal deposits, bonds, equities, life and non-life insurance, land, and housing.

Table 4 shows the results. The predicted-unconstrained/actually-unconstrained and predicted-constrained/actually-constrained cells indicate the proportion of households identified properly. The results are summarized in Table 5. As expected, the husband's educational attainment identifies unconstrained households well, as does Hayashi's indicator (his consumption-income ratio). By contrast, Zeldes's assetincome ratio is better at identifying borrowing-constrained households, but even so, about 50\% are misclassified. This finding is similar to Jappelli's (1990) finding for U.S. households that using the asset-income ratio leads to serious misclassification of constrained and unconstrained households, and moreover, misclassification is even more serious in the case of Japanese households.

Thus, we should identify unconstrained households using information on educational attainment or the consumption-income ratio, but we should identify borrowing constrained households using Zeldes's asset-income ratio despite its limitations.

\section{The Results}

\subsection{Euler Equation Test}

In this section, we present the results of our Euler equation tests, but we first present the descriptive statistics for the sample used in the estimation in Table 6.

Parts (a) and (b) of Table 7 are the results of IV estimations controlling for in- 
dividual effects using a fixed effects model and a random effects model, respectively (see Appendix (1) for the first stage regression results). Although the Wu-Hausman test shows that individual effects in the error terms are not correlated with the explanatory variables so that the random effects model is good enough to be estimated, the fixed effects model estimator is still consistent (but inefficient) and may still be preferred if unobserved time-invariant individual effects relating to the household's consumption and income changes are omitted from the equation. The coefficient of expected income is about 0.094 and 0.093 in the fixed effects and random effects models, respectively. Both coefficients are significant at the 1 percent significance level. Thus, we strongly reject the applicability of the Euler equation implication.

When we control for conditional variances additionally, the coefficients of expected income changes are still 0.097 and 0.092 , respectively, in the fixed effects model and the random effects model, and both are significant at at least the $5 \%$ significance level. Thus, we again reject the Euler equation implication.

The coefficient of expected income changes in (a) might be upward biased because the process of taking the difference from the mean (within-estimator) to remove fixed effects makes income changes "transitory or surprising" rather than "expected or permanent" whereas we want to see the reaction of consumption to the latter. A larger coefficient in the fixed effects model relative to the random effects model may reflect this possibility.

A coefficient of 0.09 or higher is roughly consistent with the values suggested by previous studies for many countries. According to the previous literature, about $9 \%$ of all households are rule-of-thumb consumers. However, we will show soon that 
comparing coefficients in this way is not meaningful. Although there is variation in the magnitude of the coefficients, the test implications are the same: the Euler equation implication is rejected. Households do not smooth consumption changes over even expected income changes.

\subsection{Do Borrowing Constraints Matter?}

Most of the past literature attributes the violation of the Euler equation implication to the existence of borrowing constraints. Using this analogy, the coefficient of expected income changes, such as the 0.09 value shown in Table 7 , is sometimes interpreted as the share of constrained households. The 0.09 value is consistent with our earlier finding that 8 to 15 percent of our sample is actually constrained.

If the existence of borrowing constraints is the reason for the violation of the Euler equation implication, we would expect to find that the Euler equation implication is applicable or close to applicable in the sample of unconstrained households. Table 8 shows the results for the sample of unconstrained households, and as this table shows, the coefficient of expected income changes stays at about the same magnitude and significance level. The difference in the coefficients of expected income changes between the full and unconstrained samples is quite small and not significant at a 1 percent significance level (see the bottom row of Table 8). Thus, the Euler equation does not hold even for unconstrained households, which suggests that the existence of borrowing constraints is not the reason for the violation of the Euler equation implication ${ }^{7}$.

\footnotetext{
${ }^{7}$ Ideally, we would have liked to estimate the Euler equation for the sample of borrowing con-
} 
Many past studies that identify unconstrained households using the level of the asset-income ratio make the conclusions even more ambiguous. In the previous section, we found that splitting the sample by the asset-income ratio itself is questionable, especially when we are interested in the behavior of unconstrained households. In addition to this problem, the sensitivity of consumption to expected income changes as measured by the above type of Euler equation does not show what proportion of households are borrowing-constrained. Nonetheless, the results obtained in this paper suggest that the existence of borrowing constraints is not the primary cause of the violation of Euler equation implication.

\subsection{Other Possible Explanations}

If borrowing constraints are not the explanation, what is the explanation for the violation of the Euler equation implication? First of all, the existence of future constraints may affect the results. Our definition of constrained households does not include the possibility of future constraints. As Hayashi (1997) emphasizes, the current consumption of households that predict that they will face borrowing constraints in the future will be sensitive to income changes. Unfortunately, we cannot identify households who expect to be constrained in the future from among currently unconstrained households.

Other data problems are also possible explanations of the rejection of the Euler

strained households also in order to see if the implication of the Euler equation was violated more strongly for this sample, as expected, but unfortunately, we were not able to do so because the sample of borrowing constrained households was too small. Wakabayashi and Horioka (2005) test the implication of the Euler equation for the full sample and for the sample of borrowing-constrained households and find that it holds for the full sample but not for the sample of borrowing-constrained households. 
equation implication. If we did not have data on total consumption but only on consumption of a certain good, we would need to assume separability between goods. If we could not obtain the appropriate micro data to test the Euler equation implication, we would have to assume that aggregation were possible. If we could not find valid instruments in the limited information set, the stochastic structure of income would be misspecified. The last problem is related to informational constraints on households. However, these problems are not so serious in the present analysis. Our consumption data is total consumption expenditure, and moreover, our data set contains data on a large number and variety of household attributes, making it easier to find appropriate instruments.

The existence of consumption durability is another possible explanation of the rejection of the Euler equation implication. If a commodity is durable and expenditure on that commodity is increased in the current period, expenditure will be depressed in the next period even though the household is still enjoying the consumption services from that commodity. Households can derive benefits from consuming now rather than later, thereby showing excess sensitivity of consumption ${ }^{8}$. In this case, the error term in Eq. (2) will contain the effects of past consumption and will be correlated with the explanatory variables (Mankiw (1982), Hayashi (1985b, 1999)). However, this problem is less serious in our case partly because our consumption measure consists primarily of non-durables and services and partly because the survey we use measures consumption in two 1-month time periods 1 year apart).

\footnotetext{
${ }^{8}$ Habit formation is another example of nonseparable consumption over time. In this case, consumption must increase over time and households try to save now for future consumption, showing excess smoothness of consumption.
} 
The existence of precautionary saving or differences in households' level of uncertainty is another possible explanation of the violation of the Euler equation implication. Our basic estimation model excludes this possibility by assuming that time and individual fixed effects can control for it, which may be too strong an assumption. The JPSC does not have information on overall uncertainty, and although we estimate the implication including consumption variances, this may not be enough to control for household's risk-related behavior.

Finally, the misspecification of the theoretical assumption that consumption and leisure are separable is another possible explanation for the violation of the Euler equation implication. Unless this assumption is imposed, we cannot derive our Euler equation test, which presupposes that the consumption decision is made independently of the leisure decision. The JPSC contains information on individual's time allocation, but it is inappropriate to examine the Euler equation implication using leisure time in the above type of income-added-test since changes in leisure are probably correlated with changes in income.

Thus, the possibility of precautionary behavior in the face of uncertainty and that of inseparability between consumption and leisure remain as topics for future research.

\section{Conclusion}

In this paper, we used micro data on young married households from the Japanese Panel Survey of Consumers, conducted by the Institute of Research on Household 
Economics, to shed light on (1) the prevalence of borrowing constraints in Japan, (2) what households are borrowing-constrained in Japan, (3) whether the life cycle/permanent income hypothesis (LCPIH) holds in Japan, and (4) whether the presence of borrowing constraints is the reason why the LCPIH does not hold in Japan. To summarize our main findings, we found (1) that 8-15 percent of young married Japanese households are borrowing-constrained, (2) that household assets and the husband's educational attainment are the most important determinants of whether or not a household is borrowing-constrained, and (3) that the Euler equation implication is rejected for both the full sample and for the subsample of unconstrained households. These results suggest that the LCPIH does not apply in Japan and that the presence of borrowing constraints is not the main reason why it does not apply.

We turn finally to the implications of our findings for the causes of the prolonged slowdown of the Japanese economy in the 1990s (the so-called "lost decade"). Many studies have found that the prolonged slowdown exacerbated the borrowing constraints of firms, which in turn caused them to cut back on their investment, hiring, and R\&D (see, for example, Ogawa (2003), but the impact of the slowdown on households via borrowing constraints does not appear to have been as pronounced. We did find that there was a sharp increase in the proportion of borrowing-constrained households during the 1990s, but even after the increase, the proportion of borrowing constrained households was less than one-sixth, and moreover, our estimation results imply that the consumption behavior of borrowing constrained household is not fundamentally any different from the consumption behavior of unconstrained 
households. Thus, it does not appear that the exacerbation of borrowing constraints on households was an important determinant of the stagnation of household consumption during the prolonged slowdown (see Horioka (2006) for a discussion of what were the main causes of the stagnation of household consumption during this period), and moreover, Horioka (2006) finds that the stagnation of household consumption contributed far less to the prolonged slowdown than the stagnation of private fixed investment. 


\section{References}

[1] Arellano, M., Bond, S., 1991. Some Tests of Specification for Panel Data: Monte Carlo Evidence and an Application to Employment Equations. Review of Economic Studies 58, 277-297.

[2] Campbell, J. H., Mankiw, G. N., 1991. The Response of Consumption to Income: A Cross-Country Investigation. European Economics Review 35, 723756.

[3] Hayashi, F., 1985a. The Permanent Income Hypothesis and Consumption Durability: Analysis Based on Japanese Panel Data. Quarterly Journal of Economics 100, 1083-1113.

[4] Hayashi, F., 1986. An Extension of the Permanent Income Hypothesis and Its Test. Keizai Bunseki (Economic Analysis) 101, 1-23, (in Japanese).

[5] Hayashi, F., 1997, Understanding Saving, The MIT Press, Cambridge, Massachusetts.

[6] Horioka, C. Y., 2006. Causes of Japan's Lost Decade: The Role of Household Consumption, Japan and the World Economy 18.

[7] Jappelli, T., 1990. Who Is Credit Constrained in the U.S. Economy? Quarterly Journal of Economics 105, 219-234. 
[8] Jappelli. T., Pistaferri, L., 2000. Using Subjective Income Expectations to Test for Excess Sensitivity of Consumption to Predicted Income Growth. European Economic Review 44, 337-358.

[9] Jappelli, T., Pischke, J., Souleles, N. S., 1998. Testing for Liquidity Constraints in Euler Equations with Complementary Data Sources. Review of Economics and Statistics 80, 251-62.

[10] Mankiw, N. G., 1982. Hall's Consumption Hypothesis and Durable Goods. Journal of Monetary Economics 10, 417-25.

[11] Ogawa, K., 1990. Cyclical Variations in Liquidity-Constrained Consumers: Evidence from Macro Data in Japan. Journal of the Japanese and International Economies 4, 173-193.

[12] Ogawa, K., 2003. Daifukyou no Keizaigaku: Nihon Keizai Chouki Teimei wo Kaimei (The Economics of the Great Recession: Explaining the Prolonged Slowdown of the Japanese Economy). Tokyo: Nihon Keizai Shinbunsha (in Japanese).

[13] Runkle, D. E., 1991. Liquidity Constraints and the Permanent-income Hypothesis. Journal of Monetary Economics 27, 73-98.

[14] Shibata, A., Shintani, M., 1998. Capital Mobility in the World Economy: An Alternative Test. Journal of International Money and Finance 17, 741-756. 
[15] Shintani, M., 1994. Nippon no Shouhisha to Ryuudousei Seiyaku (Japanese Consumers and Liquidity Constraints: A Test Based on Credit Information). Osaka Economic Papers 44, 41-56, (in Japanese).

[16] Wakabayashi, M., Horioka, C. Y., 2005. Borrowing Constraints and Consumption Behavior in Japan. Discussion Paper No. 640, Institute of Social and Economic Research, Osaka University.

[17] Zeldes, S. P., 1989. Consumption and Liquidity Constraints: An Empirical Investigation. Journal of Political Economy 97, 305-346. 


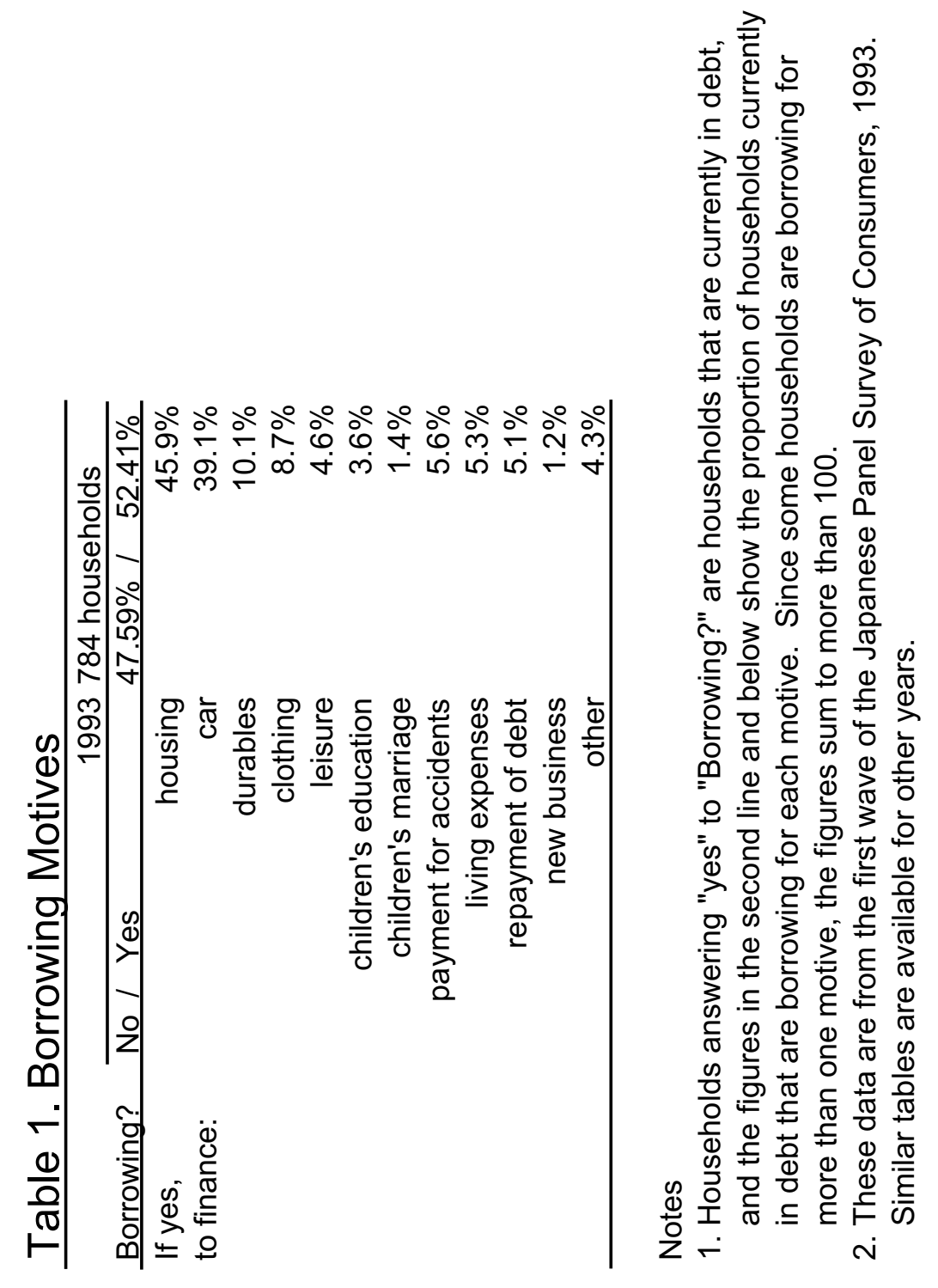



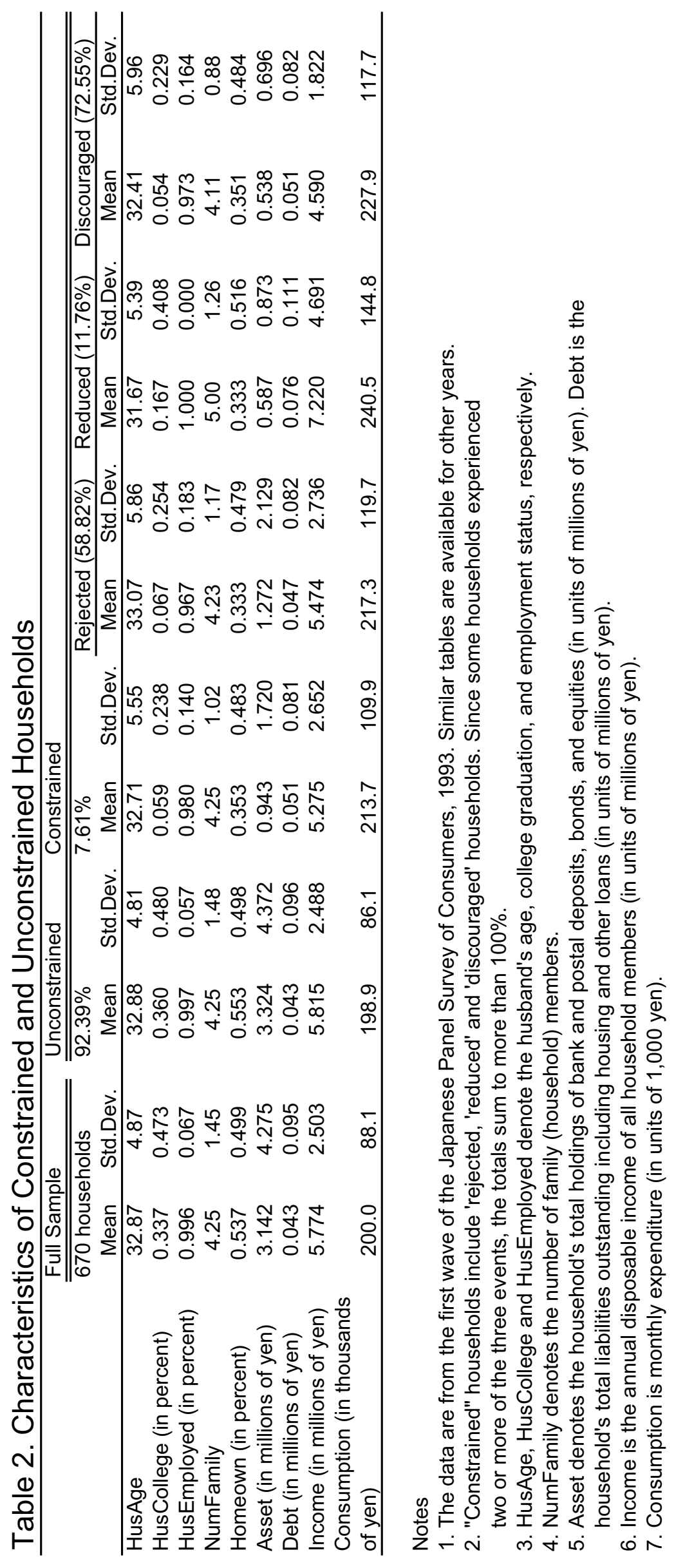
Table 3. Who Is Constrained?

Dependent Variable: "Constrained" $=1$ if either rejected, reduced, or discouraged.

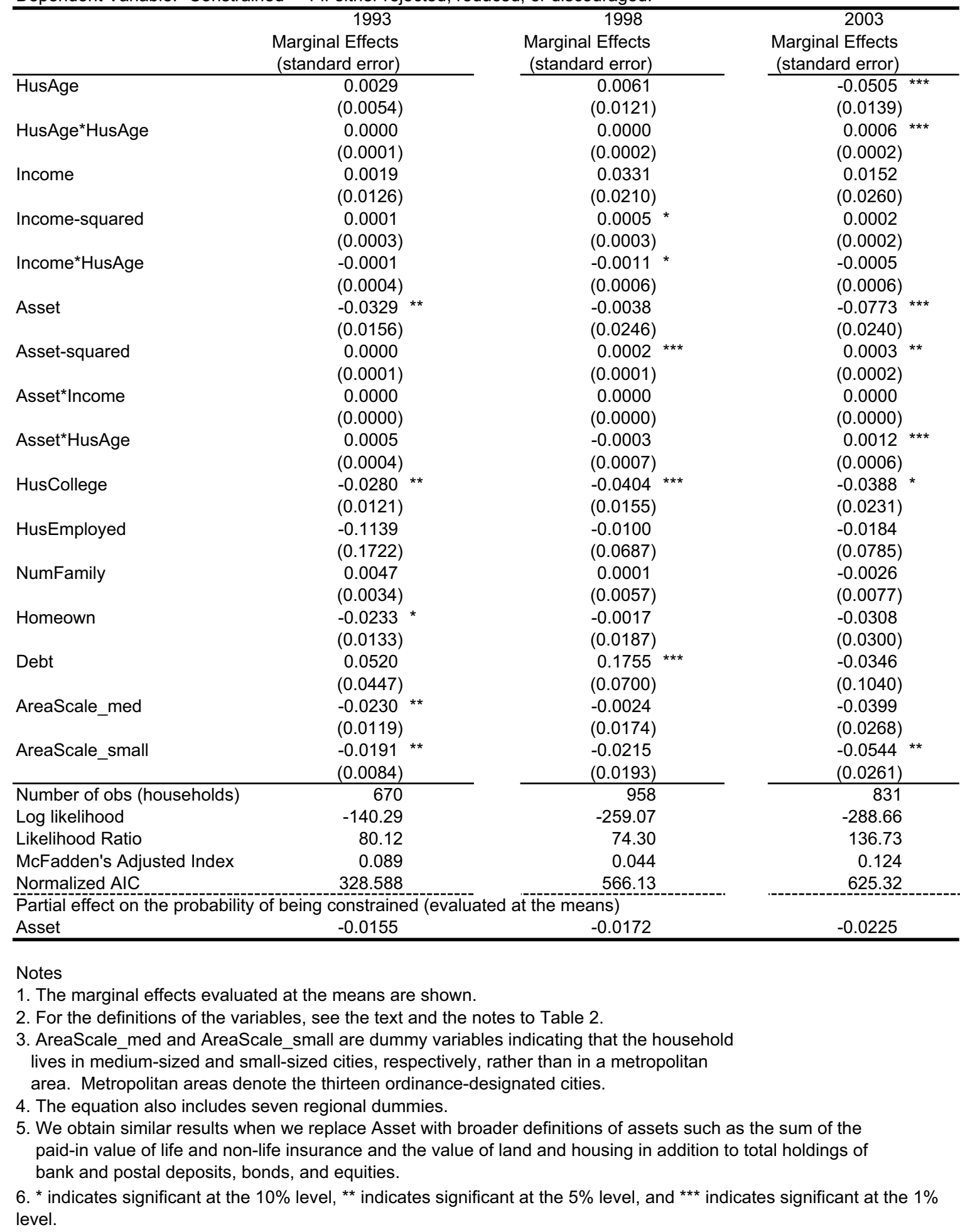



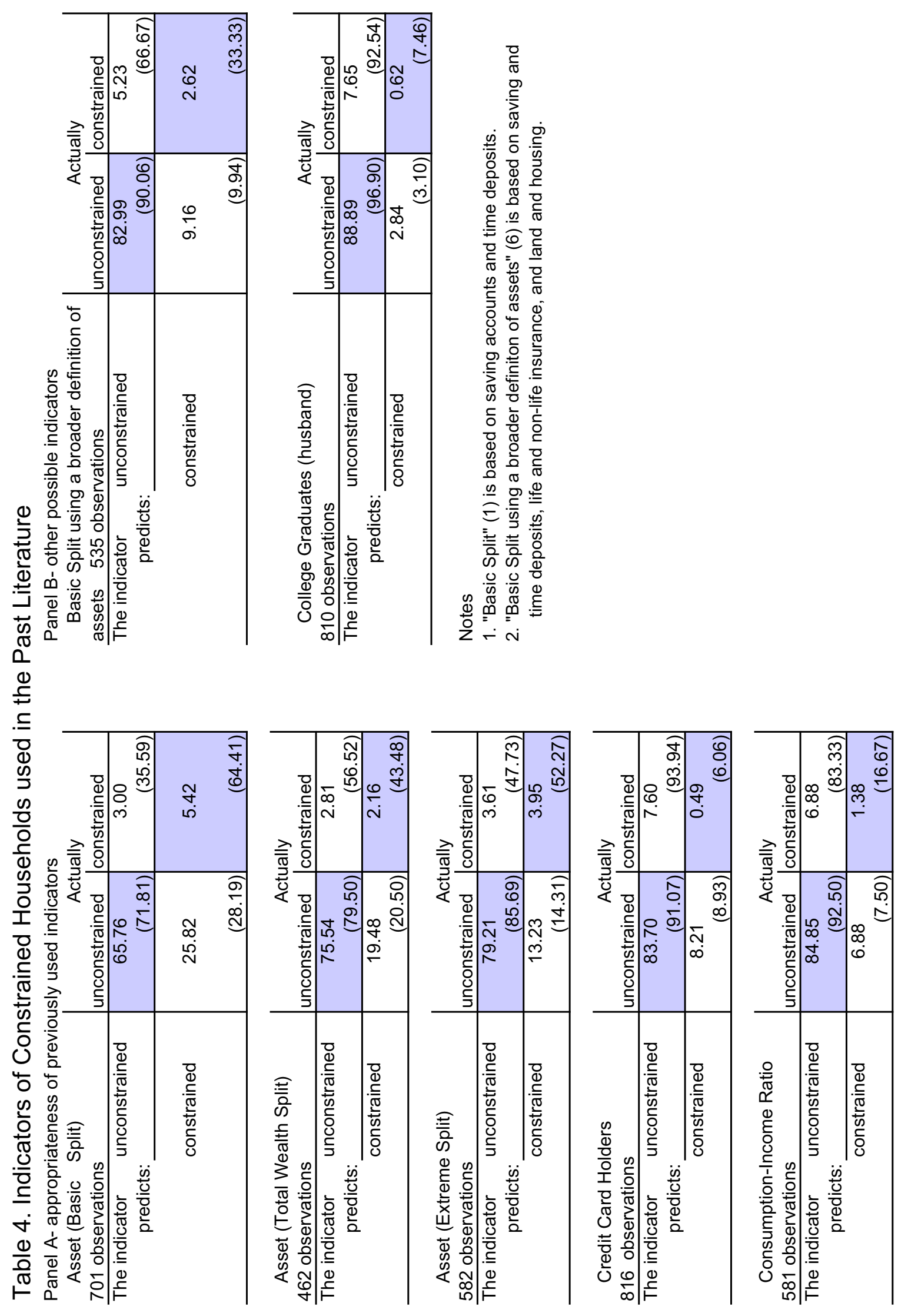


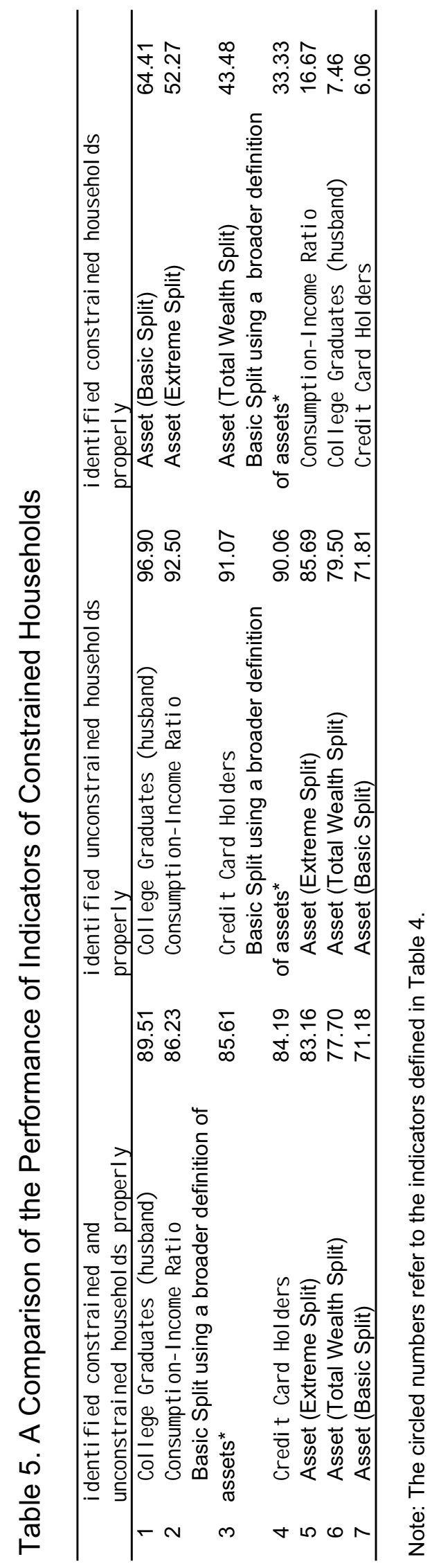




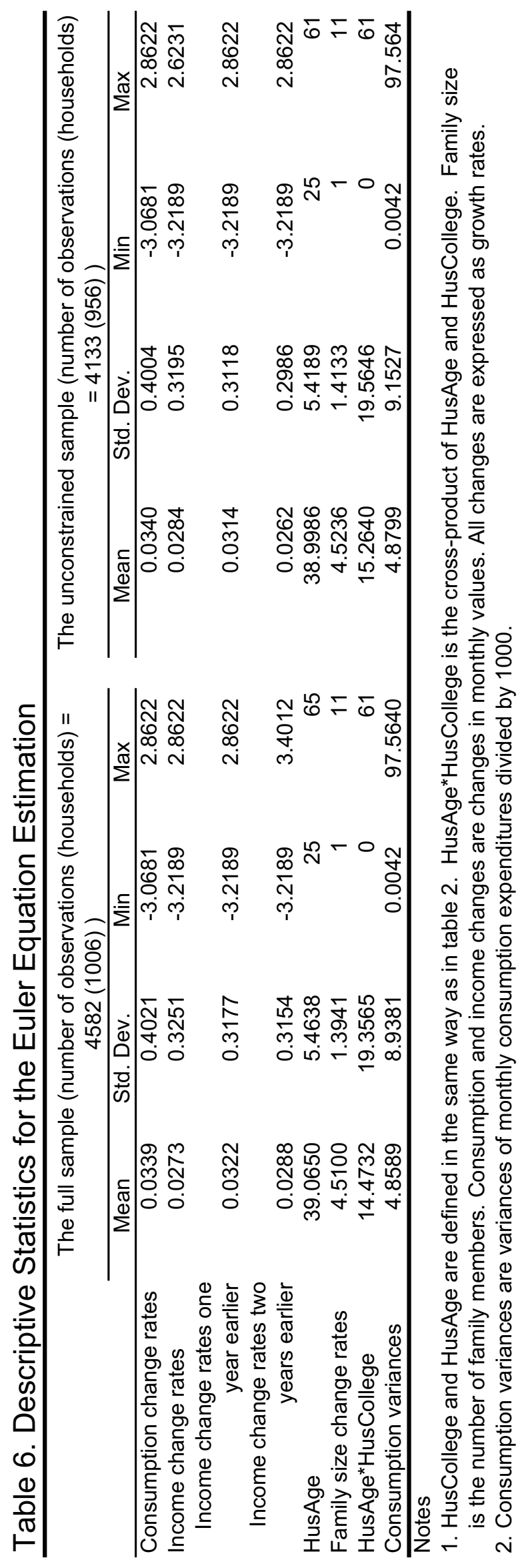




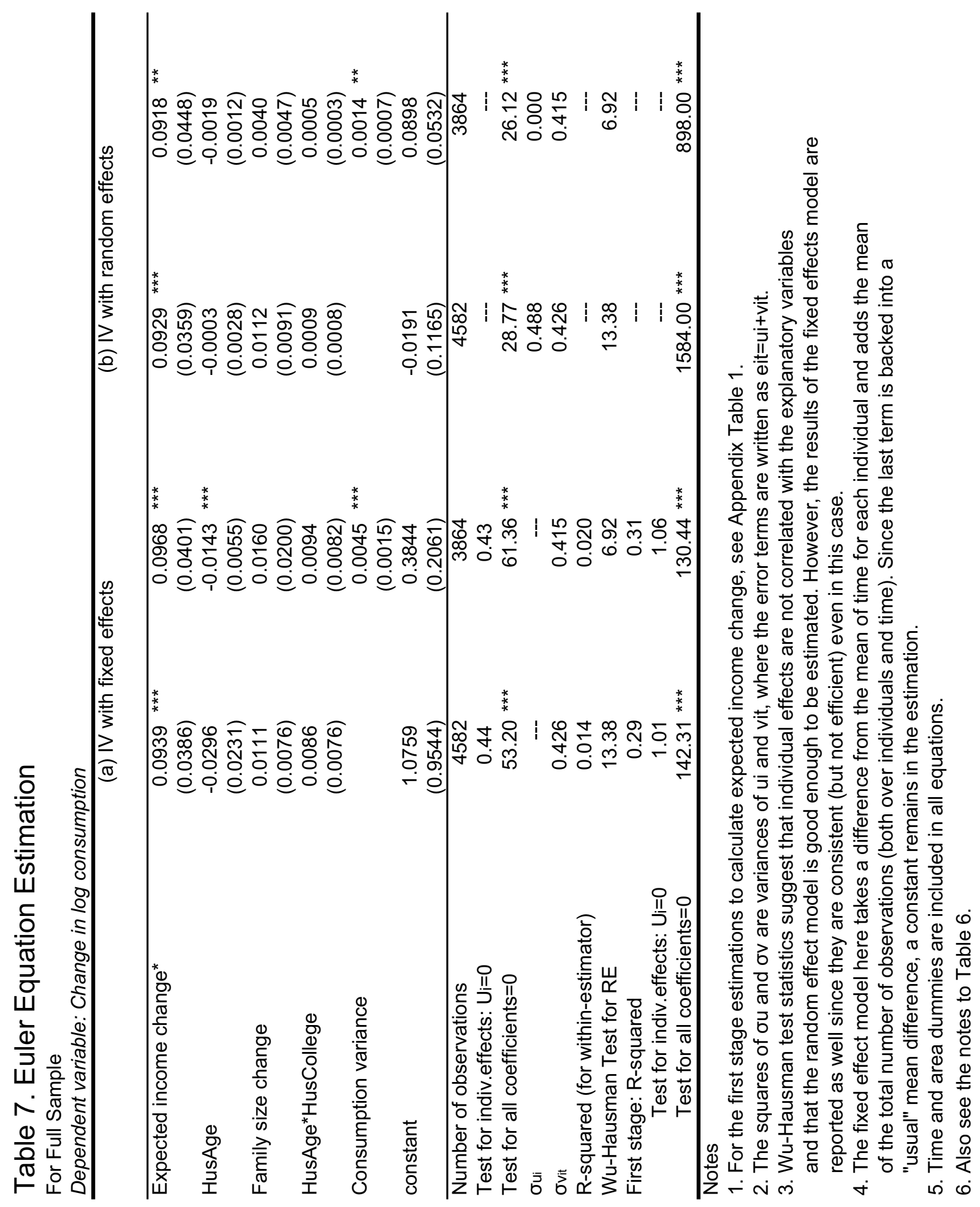




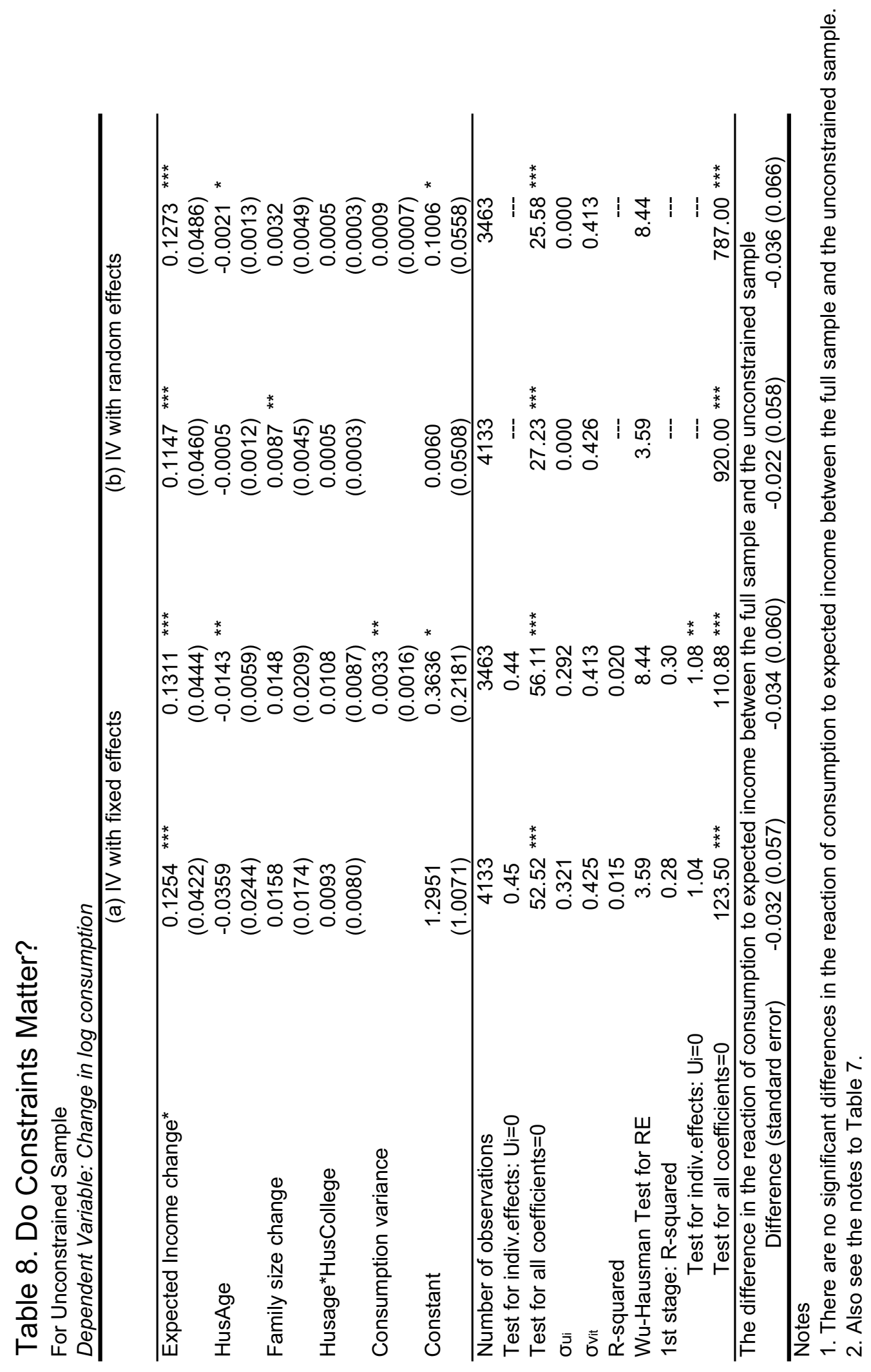


Appendix. (1) Prediction of Income Changes for Table 7 Dependent Variable: Change in log income
(a) IV with fixed effects
(b) IV with random effects

\begin{tabular}{|c|c|c|c|c|c|}
\hline Income change(t-1) & $\begin{array}{l}-0.6004^{* * *} \\
(0.0161)\end{array}$ & $\begin{array}{l}-0.61922^{* * *} \\
(0.0174)\end{array}$ & $\begin{array}{l}-0.5637^{* * *} \\
(0.0143)\end{array}$ & $\begin{array}{l}-0.4538 \\
(0.0154)\end{array}$ & *** \\
\hline Income change(t-2) & $\begin{array}{l}-0.3255^{* * *} \\
(0.0167)\end{array}$ & $\begin{array}{l}-0.3329 \\
(0.0178)\end{array}$ & $\begin{array}{l}-0.2931^{* * *} \\
0.0146\end{array}$ & $\begin{array}{l}-0.2030 \\
(0.0155)\end{array}$ & *** \\
\hline HusAge & $\begin{array}{l}-0.0161 \\
(0.0159)\end{array}$ & $\begin{array}{c}0.0028 \\
(0.0038)\end{array}$ & $\begin{array}{l}-0.0027 \\
(0.0020)\end{array}$ & $\begin{array}{l}-0.0029 \\
(0.0009)\end{array}$ & $* * *$ \\
\hline Family size change & $\begin{array}{l}0.0251 \\
(0.0115)\end{array}$ & $\begin{array}{l}0.0385^{* * *} \\
(0.0139)\end{array}$ & $\begin{array}{l}0.0172^{* * *} \\
(0.0064)\end{array}$ & $\begin{array}{c}0.0077 \\
(0.0035)\end{array}$ & ** \\
\hline HusAge ${ }^{*}$ HusCollege & $\begin{array}{l}-0.0064 \\
(0.0052)\end{array}$ & $\begin{array}{l}-0.0088 \\
(0.0057)\end{array}$ & $\begin{array}{c}0.0003 \\
(0.0006)\end{array}$ & $\begin{array}{c}0.0002 \\
(0.0002)\end{array}$ & \\
\hline Consumption variance & & $\begin{array}{c}0.0014 \\
(0.0010)\end{array}$ & & $\begin{array}{c}0.0013 \\
(0.0005)\end{array}$ & ** \\
\hline Constant & $\begin{array}{c}0.7181 \\
(0.6573) \\
\end{array}$ & $\begin{array}{l}-0.0921 \\
(0.1433)\end{array}$ & $\begin{array}{c}0.1007 \\
(0.0817) \\
\end{array}$ & $\begin{array}{c}0.1364 \\
(0.0399)\end{array}$ & \\
\hline Number of observations & 4582 & 3864 & 4582 & 3864 & \\
\hline Test for indiv.effects: $U_{i}=0$ & 1.01 & 1.06 & --- & --- & \\
\hline Test for all coefficients $=0$ & $142.31^{* * *}$ & $130.44^{* * *}$ & $1584.00^{* * *}$ & 898.00 & *** \\
\hline R-squared & 0.2852 & 0.3064 & --- & --- & \\
\hline$\sigma$ ui & -- & --- & 0.488 & 0.000 & \\
\hline$\sigma \mathrm{vit}$ & 0.294 & 0.289 & 0.426 & 0.415 & \\
\hline
\end{tabular}

Note: See the notes to Table 7.

(2) Prediction of Income Changes for Table 8

Dependent Variable: Change in log income.
(a) IV with fixed effects
(b) IV with random effects

\begin{tabular}{|c|c|c|c|c|}
\hline Income change(t-1) & $\begin{array}{l}-0.59544^{* * *} \\
(0.0171)\end{array}$ & $\begin{array}{l}-0.6075^{* * *} \\
(0.0185)\end{array}$ & $\begin{array}{l}-0.4592^{* * *} \\
(0.0155)\end{array}$ & $\begin{array}{l}-0.4517^{* * *} \\
(0.0163)\end{array}$ \\
\hline Income change(t-2) & $\begin{array}{l}-0.3301 \\
(0.0179)\end{array}$ & $\begin{array}{l}-0.3343 \\
(0.0192)\end{array}$ & $\begin{array}{l}-0.2236 \quad * * * \\
(0.0162)\end{array}$ & $\begin{array}{l}-0.21455^{* * *} \\
(0.0173)\end{array}$ \\
\hline HusAge & $\begin{array}{l}-0.0159 \\
(0.0165)\end{array}$ & $\begin{array}{c}0.0012 \\
(0.0040)\end{array}$ & $\begin{array}{l}-0.0022^{* * *} \\
(0.0009)\end{array}$ & $\begin{array}{l}-0.00288^{* * *} \\
(0.0010)\end{array}$ \\
\hline Family size change & $\begin{array}{c}0.0272 \\
(0.0117)\end{array}$ & $\begin{array}{c}0.0434^{* * *} \\
(0.0142)\end{array}$ & $\begin{array}{c}0.0117 \\
(0.0033)\end{array}$ & $\begin{array}{l}0.0098 \\
(0.0036)\end{array}$ \\
\hline HusAge*HusCollege & $\begin{array}{l}-0.0073 \\
(0.0054)\end{array}$ & $\begin{array}{l}-0.0087 \\
(0.0059)\end{array}$ & $\begin{array}{l}0.0005 * * \\
(0.0002)\end{array}$ & $\begin{array}{c}0.0003 \\
(0.0002)\end{array}$ \\
\hline Consumption variance & & $\begin{array}{c}0.0015 \\
(0.0011)\end{array}$ & & $\begin{array}{l}0.00144^{* * *} \\
(0.0005)\end{array}$ \\
\hline Constant & $\begin{array}{c}0.8725 \\
(0.6609)\end{array}$ & $\begin{array}{l}-0.0484 \\
(0.1487)\end{array}$ & $\begin{array}{l}0.08677^{* *} \\
(0.0369)\end{array}$ & $\begin{array}{l}0.1150 \\
(0.0413)\end{array}$ \\
\hline Number of observations & 4133 & 3463 & 4133 & 3463 \\
\hline Test for indiv.effects: $U i=0$ & 1.04 & 1.08 & --- & --- \\
\hline Test for all coefficients $=0$ & $123.50 * * *$ & $110.88^{* * *}$ & $920.00 * * *$ & $803.00 * * *$ \\
\hline R-squared & 0.281 & 0.299 & --- & --- \\
\hline$\sigma$ ui & --- & --- & 0.006 & 0.000 \\
\hline$\sigma \mathrm{vit}$ & 0.289 & 0.282 & 0.424 & 0.415 \\
\hline
\end{tabular}

Note: See the notes to Table 8. 